\title{
SSynthesis
}

International Scientific Conference of IT and Business-Related Research

\section{GEOMETRIJSKO MODELIRANJE UTICAJA ENERGETSKE EFIKASNOSTI NA NIVO KVALITETA POŠTANSKE USLUGE}

\author{
GEOMETRIC MODELING OF THE EFFECTS OF ENERGY EFFICIENCY ON THE QUALITY OF \\ POSTAL SERVICES
}

\author{
Milina Živanović, Dragan Lazarević, Aleksandar Trifunović \\ Univerzitet u Beogradu, Saobraćajni fakultet, Vojvode Stepe 305, Beograd, Srbija
}

\begin{abstract}
Apstrakt:
U radu se ispituje uticaj energetske efikasnosti poštanske mreže primenom geometrijskog modeliranja. Posmatrani su različiti uticajni faktori u cilju izbora rute kod optimizacije mreže poštanskog saobraćaja. Veliki značaj ima vizuelna analiza i primena geometrijskog modela za određivanje nivoa kvaliteta. Koriste se odgovarajući softverski paketi u skladu sa konceptom i principima inženjerske geometrije, koji omogućavaju visok stepen inovacije u različitim oblicima. Povećanje performansi računara i upotreba digitalne grafike visoke rezolucije olakšava kreiranje više kvalitetnih varijantnih rešenja u kratkim vremenskim rokovima. Predloženo je geometrijsko modeliranje, koje omogućava vizuelnu analizu uticaja percepirane energetske efikasnosti na nivo kvaliteta poštanske usluge na određenoj ruti mreže. Ispituje se uticaj energetske efikasnosti za izabranu rutu na mreži u cilju poboljšanja kvaliteta poštanske usluge.
\end{abstract}

\section{Ključne reči:}

geometrijski model, poštanska mreža, energetska efikasnost, kvalitet usluge.

\section{UVOD}

Savremeno drušvo karakterišu tri osnovna globalna problema: klimatske promene, ograničenost izvora energije i ekološka kriza. Saobraćaj znatno doprinosi daljem usložnjavanju ovih problema. Funkcionisanje saobraćajnog sistema uslovljeno je potrošnjom energije. Energetsko efikasni sistemi imaju visok stepen korisnog dejstva, odnosno male gubitke prilikom transformacije jednog vida energije u drugi. Moderno poslovanje i tehničko-tehnološka ekspanzija, dovode do porasta saobraćajnih zahteva, time i do porasta potrošnje goriva. $\mathrm{Na}$ energetsku efikasnost na saobraćajnoj mreži utiče: ograničenje brzine, broj pešačkih prelaza, broj raskrsnica i semafora, broj kolovoznih traka, intenzitet saobraćajnog toka, postojanje linija javnog prevoza putnika i rezervisanih “žutih” traka, otpor terena i podloge, tip vozila i goriva koje se koristi. Ovo ima značajan uticaj na: potrošnju goriva, habanje pneumatika, amortizaciju vozila i saobraćajnu infrastrukturu (International Energy Agency, 2010).

Saobraćaj je neophodan za normalno funkcionisanje društvenih i poslovnih sistema. Transport putnika, robe i prenos informacija predstavljaju saobraćajne usluge, koje omogućuju mobilnost i komunikaciju potreba korisnika. Na osnovu zahteva za prenosom pošiljaka, neophodno je odrediti rutu na poštanskoj mreži po kojoj će se kretati vozila. Pod sistemskim pristupom raspodele saobraćaja na mreži, podrazumeva se da

\section{Abstract:}

This paper analyses the impact of energy efficiency in postal network by means of geometric modeling. Different factors are examined for the purpose of selecting the route with the optimization of the network of postal services. Visual analysis and the application of geometric model play the crucial role in determining the level of quality. Appropriate software packages are used in accordance with the concept and principles of engineering geometry, thus enabling a high degree of innovation in various forms. The increase of computer performances and the use of high resolution digital graphics facilitate the creation of various high-quality solutions within the short time period. Geometric modeling is proposed as a suitable method as it enables the visual analysis of the impact of the perceived energy efficiency on the quality of postal services. This paper examines the importance of energy efficiency for the selected route on the network with the aim to improve the overall quality of postal services.

\section{Key words:}

geometric model, postal network, energy efficiency, quality of service.

težimo raspodeli tokova tako da ukupno vreme transporta kroz mrežu bude minimalno. Za nalaženje najkraćih puteva između svih parova čvorova na grafu transportne mreže koriste se poznati algoritmi. Za kreiranje i izbor rute, mogu se koristiti i specijalizovani sistemi za podršku odlučivanju zasnovani na algoritmima, globalnim pozicionim sistemima (GPS), geografskim informacionim sistemima (GIS), podacima iz inteligentnih transportnih sistema (ITS). Ovi sistemi primenjuju ograničenja, koja uslovljavaju minimizaciju puta ili vremena.

U ovom radu se razmatra mogućnost primene geometrijskog modeliranja uticaja energetske efikasnosti na nivo kvaliteta poštanske usluge na poštanskoj mreži. Poštanska mreža se povezuje na tri nivoa:

1. između poštanskih centara,

2. poštanskog centra sa jedinicom poštanske mreže,

3. jedinica poštanske mreže sa korisnikom.

$\mathrm{U}$ ovom radu je primenjeno geometrijsko modeliranje za merenje nivoa kvaliteta usluge na mreži (Živanović, 2003; Živanović, 2009) i predložen geometrijski model uticaja energetske efikasnosti na kvalitet poštanske usluge. Obavljanje poštanskih usluga moguće je različitim vidovima saobraćaja. Posebno se razmatra poštanska mreža u kojoj se koriste drumska transportna sredstva. Moguće je primeniti predloženi geometrijski model uticaja energetske efikasnosti na kvalitet poštanske usluge na nivou 1 i 2. 


\section{OPIS PARAMETRA ENERGETSKE EFIKASNOSTI}

Energetska efikasnost saobraćajne mreže zavisi od energetske efikasnosti pojedinih ruta. Percipirana energetska efikasnost na određenoj ruti rR može biti: „niska - nezadovoljavajuća”, „prihvatljiva” ili „visoka - zadovoljavajuća” što se može predstaviti fuzzy skupovima sa odgovarajućim funkcijama pripadnosti. Prema (Zadeh, 1965) definišemo:

- „nisku - nezadovoljavajuću” energetsku efikasnost na odredjenoj ruti $r \in R$ kao fuzzy skup $N E$ :

$$
N E=\left\{e, \mu_{N E}(e) e \in E\right\}
$$

sa funkcijom pripadnosti:

$$
\mu_{N E}(e)=\left\{\begin{array}{cc}
1, & e \leq e_{1} \\
1-\mu_{E}(e), & e_{1} \leq e \leq e_{2} \\
0, & e \geq e_{2}
\end{array}\right\}
$$

Funkcija pripadnosti $\mu_{\mathrm{NE}}(e)$, svakoj tački $e \in E$, pridružuje realan broj iz intervala $[0,1]$, gde su:

$e 1$ - najmanja vrednost percepirane energetske efikasnosti $e$ na određenoj ruti $r \in R$,

$e 2$ - najviše očekivana vrednost percepirane energetske efikasnosti $e$ na određenoj ruti $r \in R$,

$e 3$ - najveća vrednost percepirane energetske efikasnosti $e$ na određenoj ruti $r \in R$.

Za percepiranu energetsku efikasnost $e$ na određenoj ruti $r \in R$, koja je manja od $e 1$, smatramo da apsolutno pripada domenu fuzzy skupa $N E$ (stepen pripadnosti $\mu=1$ ).

Vrednost energetske efikasnosti od $e 1$ do $e 2$, pripada domenu fuzzy skupa $N E$, sa stepenom pripadnosti između 0 i 1 , dok veće od $e 2$, ne pripada domenu fuzzy skupa $N E(\mu=0)$.

- „prihvatljivu” energetsku efikasnost $e$ na određenoj ruti $r \in R$ kao fuzzy skup $\boldsymbol{E}$ :

$$
E=\left\{e, \mu_{E}(e) e \in E\right\}
$$

čija je funkcija pripadnosti $\mu \mathrm{E}(\mathrm{e})$, svakoj tački $e \mathrm{E}$, pridružuje realan broj iz intervala $[0,1]$ i definisana je izrazom:

$$
\mu_{E}(e)=\left\{\begin{array}{cc}
0, & e \leq e_{1}, \quad e \geq e_{3} \\
\frac{\left(e-e_{1}\right)}{\left(e_{2}-e_{1}\right)}, & e_{1} \leq e \leq e_{2} \\
\frac{\left(e_{3}-e\right)}{\left(e_{3}-e_{2}\right)}, & e_{2} \leq e \leq e_{3}
\end{array}\right\}
$$

Za percepiranu vrednost energetske efikasnosti manju od $e 1$ i veću od $e 3$ smatramo da apsolutno ne pripada domenu fuzzy skupa $E$ (stepen pripadnosti $\mu=0$ ). Vrednost energetske efikasnosti od $e 1$ do $e 3$, pripada domenu fuzzy skupa $E$ sa stepenom pripadnosti između 0 i 1.

- „visoku - zadovoljavajuću” energetsku efikasnost $e$ na određenoj ruti $r \in R$ kao fuzzy skup $V E$ :

$$
V E=\left\{e, \mu_{V E}(e) \mid e \in E\right\}
$$

pri čemu je funkcija pripadnosti:

$$
\mu_{V E}(e)=\left\{\begin{array}{cc}
0, & e \leq e_{2} \\
1-\mu_{E}(e), & e_{2} \leq e \leq e_{3} \\
1, & e \geq e_{3}
\end{array}\right\}
$$

Funkcija pripadnosti $\mu \mathrm{VE}(\mathrm{e})$, svakoj tački $e \in E$, pridružuje realan broj iz intervala $[0,1]$. Za percepiranu vrednost energetske efikasnosti $e$ na određenoj ruti $r \in R$, manju od $e 2$, smatramo da apsolutno ne pripada domenu fuzzy skupa VE ( stepen pripadnosti $\mu=0$ ). Vrednost energetske efikasnosti od $e 2$ do e3, pripada domenu fuzzy skupa VE, sa stepenom pripadnosti između 0 i 1 , dok veća od $e 3$, apsolutno pripada domenu fuzzy skupa VE $(\mu=1)$.

Predstavljene su funkcije pripadnosti fuzzy skupovima $N E$, E i $\boldsymbol{V E}$ (Sl. 1.).

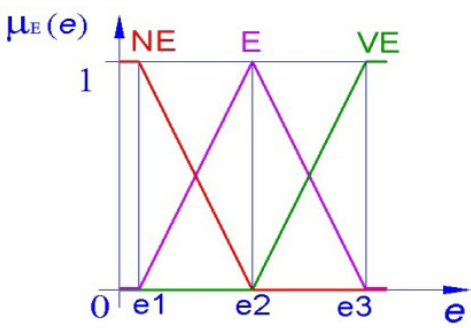

Slika 1. Percipirana energetska efikasnost na određenoj ruti $r \in R$ poštanske mreže

\section{GEOMETRIJSKO MODELIRANJE UTICAJA ENERGETSKE EFIKASNOSTI NA NIVO KVALITETA POŠTANSKE USLUGE}

\begin{tabular}{|c|c|c|c|c|c|}
\hline \multirow{2}{*}{$\begin{array}{l}\text { parametar } \\
\text { kvaliteta }\end{array}$} & \multirow{2}{*}{$\begin{array}{l}\text { fuzzy } \\
\text { skup }\end{array}$} & \multicolumn{4}{|c|}{ ravan } \\
\hline & & $\mathrm{t}$ & $\mathrm{e}$ & $\mathrm{p}$ & ograničenje \\
\hline vreme otpreme & A & 0 & $\propto$ & 1 & $\mathrm{k}=1$ \\
\hline vreme prijema & B & 0 & $\propto$ & 1 & $\mathrm{k}=1$ \\
\hline vreme vožnje & $\mathrm{C}$ & $\mathrm{t}_{\mathrm{v}}$ & $\propto$ & 1 & $\mathrm{k}=1$ \\
\hline vreme dostave & $\mathrm{D}$ & 0 & $\propto$ & 1 & $\mathrm{k}=1$ \\
\hline $\begin{array}{l}\text { niska energetska } \\
\text { efikasnost }\end{array}$ & $\mathrm{NE}$ & $\propto$ & $e_{1}$ & 0.4 & $\mathrm{t}=\mathrm{t}_{\mathrm{v}}$ \\
\hline $\begin{array}{l}\text { srednja energetska } \\
\text { efikasnost }\end{array}$ & $\mathrm{E}$ & $\propto$ & $e_{2}$ & 0.6 & $t=t_{v}$ \\
\hline $\begin{array}{l}\text { visoka energetska } \\
\text { efikasnost }\end{array}$ & $\mathrm{VE}$ & $\propto$ & $e_{3}$ & 0.8 & $\mathrm{t}=\mathrm{t}_{\mathrm{v}}$ \\
\hline
\end{tabular}

Za percepiranu „nisku - nezadovoljavajuću”, „prihvatljivu” ili „visoku - zadovoljavajuću” energetsku efikasnost definisanu fuzzy skupovima sa odgovarajućim funkcijama pripadnosti prema $(1,2,3,4,5,6)$ na Sl. 1 na primeru zadatih vrednosti prikazanih tabelarno posmatrano u odnosu na idealan slučaj biće:

Tabela 1. Parametri kvaliteta, fuzzy skupovi i položaji ravni za „nisku - nezadovoljavajuću”, „prihvatljivu” ili „visoku zadovoljavajuću” energetsku efikasnost

Na osnovu Tabele 1. možemo videti na Sl. 2. položaje ravni za izabrane vrednosti, koje odgovaraju datom primeru kada je „niska - nezadovoljavajuća”, „prihvatljiva” $i$ „visoka - zadovoljavajuća" energetska efikasnost. Razlika u odnosu na idealan slučaj maksimalnog nivoa kvaliteta poštanske usluge uočava se upoređenjem. 


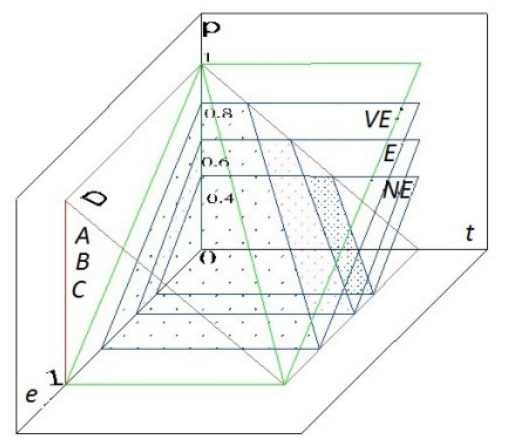

Slika 2. Položaji ravni za „nisku-nezadovoljavajuću”, „prihvatljivu” ili „visoku - zadovoljavajuću” energetsku efikasnost

$\mathrm{Na}$ Sl. 3. prikazan je poliedar, koji se dobija međusobnim presekom ravni u prvom oktantu, a čija zapremina predstavlja meru nivoa kvaliteta poštanske usluge za „nisku - nezadovoljavajuću" energetsku efikasnost.

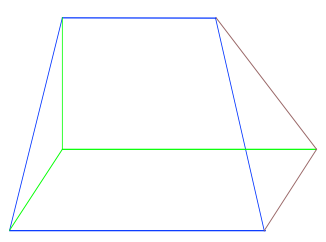

Slika 3. Poliedar, čija zapremina reprezentuje nivo kvaliteta poštanske usluge za „nisku - nezadovoljavajuću” energetsku efikasnost

Na Sl. 4. prikazan je poliedar, koji se dobija međusobnim presekom ravni u prvom oktantu, a čija zapremina predstavlja meru nivoa kvaliteta poštanske usluge za "prihvatljivu” energetsku efikasnost.

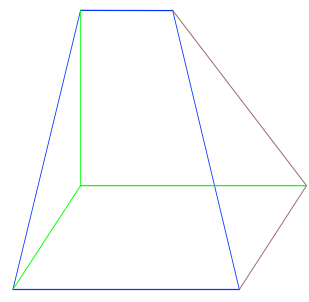

Slika 4. Poliedar, čija zapremina reprezentuje nivo kvaliteta poštanske usluge za „prihvatljivu” energetsku efikasnost

Na Sl. 5. prikazan je poliedar, koji se dobija međusobnim presekom ravni u prvom oktantu, a čija zapremina predstavlja meru nivoa kvaliteta poštanske usluge za visoku energetsku efikasnost.

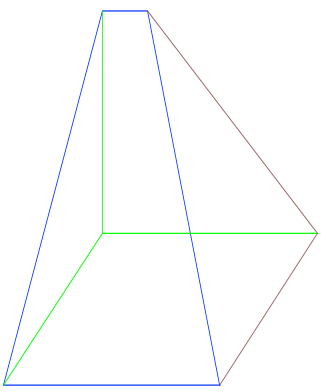

Slika 5. Poliedar, čija zapremina reprezentuje nivo kvaliteta poštanske usluge za „visoku - zadovoljavajuću” energetsku efikasnost

Analizom uticaja parametra energetske efikasnosti na nivo kvaliteta poštanske usluge na mreži, zaključujemo prema položajima ravni na Sl. 2, da viša energetska efikasnost utiče na povećanje nivoa kvaliteta poštanske usluge. Dobijeni poliedri su sve veće zapremine, što se vidi poređenjem Slika 3, 4 i 5.

\section{REZIME}

Analiziran je uticaj energetske efikasnosti za izabranu rutu na mreži u cilju poboljšanja kvaliteta poštanske usluge. Pri opredeljenju donosi se odluka na osnovu percepiranih vrednosti parametara kvaliteta usluge. Zaključivanje se izvodi na osnovu nepreciznih i nejasno definisanih subjektivnih informacija i znanja. Rezonovanje se vrši parcijalnim slaganjem. Geometrijskim modeliranjem uticaja percepirane energetske efikasnosti na određenoj ruti mreže može se zaključiti da viša energetska efikasnost utiče na povećanje nivoa kvaliteta nudioca usluge. Poliedri koji reprezentuju nivo kvaliteta usluge su sve veće zapremine, što se vidi upoređenjem Sl. 3, 4 i 5. te je i nivo kvaliteta transportne usluge viši. Razlika u odnosu na idealan slučaj maksimalnog nivoa kvaliteta poštanske usluge uočava se upoređenjem.

\section{LITERATURA}

International Energy Agency. (2010). Transport Energy Efficiency. Preuzeto 18. Januara 2015. sa https://www.iea.org/publications/freepublications/publication/transport_energy_efficiency.pdf

Zadeh, L.A. (1965). Fuzzy Sets. Information and Control. 8, 338353.

Živanović, M. (2003). Geometric Model of Measuring Service Quality. Communication in Dependability and Quality Management. 6(1), 7-12.

Živanović, M. (2009). Transport Service Quality of Network. Dependability and Quality Management : proceedings / 12th International Conference ICDQM-2009, june 25-26, 2009, Belgrade. 1, 840-846. 